Article

\title{
Certified Motorcycle Helmets: Computational Evaluation of the Efficacy of Standard Requirements with Finite Element Models
}

\author{
Fábio A. O. Fernandes ${ }^{1, *}$, Ricardo J. Alves de Sousa ${ }^{1}\left({ }\right.$, Mariusz Ptak $^{2}(\mathbb{D}$ and \\ Johannes Wilhelm ${ }^{2} \mathbb{D}$ \\ 1 TEMA - Centre for Mechanical Technology and Automation, Department of Mechanical Engineering, \\ University of Aveiro, Campus de Santiago, 3810-193 Aveiro, Portugal; rsousa@ua.pt \\ 2 Department of Machine Design and Research, Faculty of Mechanical Engineering, Wroclaw University of \\ Science and Technology, Lukasiewicza 7/9, 50-371 Wroclaw, Poland; mariusz.ptak@pwr.edu.pl (M.P.); \\ johannes.wilhelm@pwr.edu.pl (J.W.) \\ * Correspondence: fabiofernandes@ua.pt; Tel.: +351-234-370830
}

Received: 27 January 2020; Accepted: 11 February 2020; Published: 16 February 2020

\begin{abstract}
Every year, thousands of people die in the European Union as a direct result of road accidents. Helmets are one of the most important types of personal safety gear. The ECE R22.05 standard, adopted in 2000, is responsible for the certification of motorcycle helmets in the European Union and in many other countries. Two decades later, it is still being used with the same requirements, without any update. The aim of this work is to evaluate the efficacy of a motorcycle helmet certified by such standard, using computational models as an assessment tool. First, a finite element model of a motorcycle helmet available on the market was developed and validated by simulating the same impacts required by the standard. Then, a finite element model of the human head is used as an injury prediction tool to assess its safety performance. Results indicate a significant risk of brain injury, which is in accordance with previous studies available in the literature. Therefore, this work underlines and emphasizes the need of improving the requirements of ECE R22.05.
\end{abstract}

Keywords: crashworthiness; finite element model; head impact; helmet; numerical simulation; traumatic brain injury

\section{Introduction}

Road accidents are one of the major causes of death in the world, 1.35 million deaths each year, and is the main cause of death for children and young adults (5-29 years of age) [1]. Every year, thousands of people lose their lives or are seriously injured in accidents on EU roads [2]. In 2017, 14\% of a total of 25,300 deaths due to road accidents in EU involved motorcyclists [2]. ECE R22.05 is the European helmet safety standard responsible for the certification of motorcycle helmets, also being recognized outside the EU [3]. It was adopted in 2000 and is currently recognized by 62 countries and is the most widespread helmet standard. Twenty years have passed since its adoption and the requirements are exactly the same. 
Nowadays, the majority of helmet standards are targeted with criticism involving their test methods and certification criteria. During the last two decades, effort has been made by the scientific community in the area of road helmet safety, from the biomechanics of head injuries to new solutions in terms of materials and devices. In some studies, the criterion used by ECE R22.05 is criticized since it does not take into account the rotational component, relying only on the maximum value of linear acceleration (PLA) and on the linear acceleration-time history through the head injury criterion (HIC) [4]. Although the latter takes into account impact duration, many researchers have been criticizing HIC for several reasons, such as for not taking into consideration the rotational acceleration, impact direction and head size and also for having nonsensical units [5-13].

Although the rotational motion is disregarded by ECE R22.05, the rotational acceleration is always present in real motorcyclists' accidents [14] and has a tremendous effect on brain injuries [15]. For instance, motorcycle accidents involving helmeted impacts and that usually result in severe injuries are frequently associated with rotational forces $[16,17]$. When these forces act on the head, the results are large strains in the brain, which have been proposed as a cause of severe traumatic brain injury (TBI), for instance diffuse axonal injury (DAI) and subdural hematoma (SDH) due to the tear of neuronal axons in brain tissue and the rupture of bridging veins, respectively $[18,19]$.

Newman [20] also highlighted these issues, as well as the continued use of outmoded test methods that do not properly reflect the real circumstances of accidents such as the headform biofidelity, the nature of the failure criteria and the impact kinematics, which influences the movement of a tested helmeted headform. In another study, Pratellesi et al. [21] tested uncertainties regarding the certification procedure in ECE R22.05 standard. Finite element (FE) simulations revealed that the HIC value is changed by up to $30 \%$ by testing uncertainties that are in total agreement with the corresponding standard. This fact casts its credibility into doubt since a deviation of $30 \%$ is not within a tolerable range for a safety issue.

Overall, there is a general consensus that helmets are designed, manufactured and tested to meet the standards requirements, with lower consideration for biomechanical findings [22,23]. An optimization based on biomechanical criteria (e.g., intracranial pressure, shear strain, etc.) is different from the optimization based on HIC, which, in the case of helmet certification is based and highly dependent on the acceleration of a rigid headform [24]. Successful prevention relies on a sound understanding of injury mechanisms and knowledge of the biomechanical responses [25]. Currently, it is well known that helmets substantially reduce head injury, being undoubtedly safer to wear a helmet rather than none. Nonetheless, helmets are primarily designed to reduce headform linear deceleration, instead of focusing directly on head injury prevention [23,26-29].

Virtual testing makes it possible to assess the influence of a large number of parameters in a cheaper and more flexible way than experimental testing. Advanced FE models of helmets have been developed, accurately modeling its components geometry, material properties, contact/interactions, etc. Some of these models were developed with the goal to optimize the helmet design according to specific criteria $[23,27,28,30-38]$. These coupled with FE head models make it possible to predict traumatic brain injuries [39-49].

FE head models have been evolving over the decades, from rough spherical or ellipsoidal volumes modeled as linear elastic materials to accurate modeling of cerebral sulci and gyri structures with non-linear material models. For instance, in recent works, cerebral vasculature and fluid-structure interaction (FSI) models have been developed [50,51], respectively. Once validated, these numerical models make it possible to compute several variables, not only from the impacted helmet but also from the human head. For instance, these numerical models have been used to optimize the helmet design based on the injury predictions computed with FE head models [23,34]. 
The aim of this work is to evaluate the efficacy of a motorcycle helmet certified by ECE R22.05. First, an FE model of a motorcycle helmet available on the market and its validation are presented. This validation is in regards to the acceleration measured at the headform center of gravity during the linear impacts defined in the ECE R22.05 standard. Then, an FE model of the human head is used as an injury prediction tool to assess its safety performance.

\section{Materials and Methods}

In this work, a motorcycle helmet certified by the ECE R22.05 standard is assessed with an FE head model, by simulating the energy absorption tests prescribed by the same standard and used to validate the FE motorcycle helmet model. The safety level of this helmet was assessed based on the head injury risk predictions by the YEt Another Head Model (YEAHM), previously developed by the authors [39,52]. A similar analysis was previously carried out in [24]. However, this one was performed with a different FE head model and only one impact point was assessed. The present work aims to provide a broader analysis.

\subsection{Motorcycle Helmet Model}

\subsubsection{Numerical Modeling}

In this work, a motorcycle helmet that fully meets the ECE R22.05 regulation [3] was modeled (Figure 1). The overall geometry of the helmet was provided by the manufacturer. Nevertheless, an arduous stage of geometric modeling was still necessary in order to have a geometrically accurate FE mesh. The geometry of the different parts that compose the helmet was improved in CATIA software and then, these parts were meshed in Abaqus.
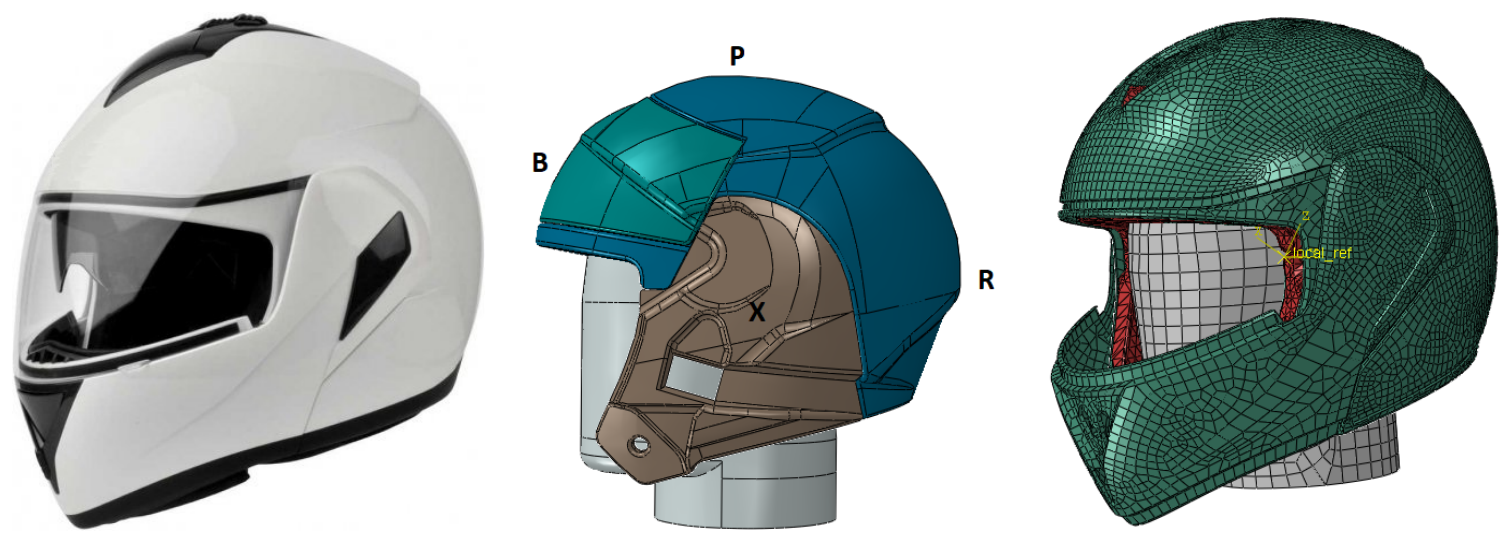

Figure 1. Certified motorcycle helmet and the developed finite element (FE) model.

The developed FE helmet model is composed by a shell and by a multi-part liner. The latter is composed by four parts, having two lateral liners on the temporal region (left lateral liner in brown in Figure 1). These were considered the main and most important helmet parts regarding its impact performance. In the literature, it is rare to find a study where the comfort padding was modeled. In one exception, Brands et al. [53] modeled the comfort liner and concluded that its effect is negligible. In addition, Pinnoji and Mahajan [54] affirmed that this extremely soft foam does not contribute to energy absorption, being used only for fitting helmets to different head sizes. As a result of its low stiffness, the comfort foam deforms completely without absorbing any relevant amount of energy, and therefore, has no direct influence in impact protection [55]. Thus, comfort padding does not have influence on the headform's response during an impact [56]. Therefore, from a cost-benefit ratio, the comfort padding was not modeled. 
The expanded polystyrene (EPS) liners thickness varies from $20 \mathrm{~mm}$ to $50 \mathrm{~mm}$. The thicker one that covers the top of the head varies mostly between 40 and $50 \mathrm{~mm}$, being only thinner at the low rear region. On the other hand, the thickness of the lateral ones varies from 20 to $40 \mathrm{~mm}$, being also thinner at the low rear. The outer shell made of acrylonitrile butadiene styrene (ABS) has a thickness of $3 \mathrm{~mm}$.

According to ECE R22.05 regulation, for the size of this helmet, a $5.6 \mathrm{~kg}$ headform should be used (M size). The developed FE headform model is shown in Figure 1 and its inertial characteristics are given in Table 1.

Table 1. Headform mass and principal inertial moments.

\begin{tabular}{cccc}
\hline Mass $[\mathrm{kg}]$ & $I_{x x}\left[\mathrm{~kg} \mathrm{~cm} \mathbf{~ c}^{2}\right]$ & $I_{y y}\left[\mathrm{~kg} \mathrm{~cm}{ }^{2}\right]$ & $I_{z z}\left[\mathrm{~kg} \mathrm{~cm}{ }^{2}\right]$ \\
\hline 5.6 & 370 & 440 & 300 \\
\hline
\end{tabular}

Four-node linear tetrahedral elements were employed to mesh the liner. This type of element was used mainly due to its complex geometry. On the other hand, the shell was modeled with four-node linear shell elements with enhanced hourglass control. The headform and the flat anvil were modeled with rigid quadrangular elements. Although the ECE R22.05 standard requires more than one anvil, only the flat anvil was modeled because it is the most impacted object (e.g., road surface) in motorcycle crashes involving head impact $[57,58]$.

The meshes were created always avoiding distorted and warped elements. Additionally, special attention was given to the time increment, not having very small elements in order to have a reasonable computation time but at the same time a mesh refined enough to obtain precise results. In order to verify the mesh influence, a mesh convergence analysis was carried out by varying the mesh density. A summary of the meshes, including the element types, integration schemes and mesh density, is presented in Table 2.

Table 2. Mesh characteristics of the helmet model.

\begin{tabular}{llrr}
\hline Part & Element Type (Abaqus) & N. of Elements & N. of Nodes \\
\hline Shell & Four-node linear shell (S4) & 11,954 & 12,310 \\
Liner & Four-node linear tetrahedron (C3D4) & 109,872 & 24,545 \\
\hline Headform & \multirow{2}{*}{ Rigid quadrangular shell (R3D4) } & 1346 & 1348 \\
Anvil & & 4 & 9 \\
\hline
\end{tabular}

In order to simulate the interactions between the headform and the liner and also the interactions between the anvil and the shell, a surface-to-surface type of contact with friction coefficients of 0.55 and 0.5 were used, respectively [59]. Also, a tie was used to simulate the interaction between glued parts.

According to the ECE R22.05 standard, the helmet-headform system is dropped, without any restriction, against an anvil with at $7.5 \mathrm{~m} / \mathrm{s}$. During the impact test, the acceleration is measured and recorded thanks to a built-in triaxial accelerometer positioned at the center of gravity (COG) of the rigid headform. Thus, the anvil is fully constrained and an impact velocity of $7.5 \mathrm{~m} / \mathrm{s}$ was prescribed to the helmet-headform model. ECE R22.05 standard requires four impact configurations, the B (frontal), $\mathrm{P}$ (vertex), R (back) and X (lateral) impact points. The explicit solver of Abaqus was used to simulate the impacts.

\subsubsection{Material Modeling}

In order to simulate the helmeted impacts, it was necessary to choose suitable constitutive material models to simulate the mechanical behavior of each material. Two different materials were modeled, EPS and ABS. The EPS foam was modeled as an elasto-plastic material. The elastic part is specified as linear isotropic elasticity, as described by Equations (1)-(3). The Young's modulus of EPS is $36 \mathrm{MPa}$ and it has a null Poisson's ratio. 


$$
\begin{gathered}
\sigma=D^{e l} \epsilon^{e l} \\
\left\{\begin{array}{l}
\epsilon_{11} \\
\epsilon_{22} \\
\epsilon_{33} \\
\gamma_{11} \\
\gamma_{33}
\end{array}\right\}=\left[\begin{array}{cccccc}
1 / E & -v / E & -v / E & 0 & 0 & 0 \\
-v / E & 1 / E & -v / E & 0 & 0 & 0 \\
-v / E & -v / E & 1 / E & 0 & 0 & 0 \\
0 & 0 & 0 & 1 / G & 0 & 0 \\
0 & 0 & 0 & 0 & 1 / G & 0 \\
0 & 0 & 0 & 0 & 0 & 1 / G
\end{array}\right]\left\{\begin{array}{l}
\sigma_{11} \\
\sigma_{22} \\
\sigma_{33} \\
\sigma_{12} \\
\sigma_{13} \\
\sigma_{23}
\end{array}\right\} \\
G=E / 2(1+v)
\end{gathered}
$$

In order to simulate the plastic behavior, the crushable foam material model was employed. This model is intended for the analysis of crushable foams that are typically used as energy absorption structures. In this plastic model, the yield surface is a von Mises circle in the deviatoric stress plane and an ellipse in the meridional $(p-q)$ stress plane [60]. The crushable foam model with volumetric hardening uses a yield surface with an elliptical dependence of deviatoric stress on pressure. A point on the yield ellipse in the meridional plane that represents hydrostatic tension loading is fixed and the evolution of the yield surface is driven by the volumetric compacting plastic strain [60]. Thus, it assumes that the evolution of the yield surface is controlled by the volumetric compacting plastic strain experienced by the material. The yield surface for the volumetric hardening model is defined as:

$$
F=\sqrt{q^{2}+\alpha^{2}\left(p-p_{0}\right)^{2}}-B=0
$$

$$
\begin{array}{ll}
p=-\frac{1}{3} \operatorname{tr}(\sigma) & \text { is the pressure; } \\
q=\sqrt{\frac{3}{2} \mathbf{S}: \mathbf{S}} & \begin{array}{l}
\text { is the von Mises stress; } \\
\mathbf{S}=\sigma+p \mathbf{I}
\end{array} \\
\begin{array}{l}
\text { is the deviatoric stress and } \mathbf{I} \text { is the identity matrix; } \\
B=\alpha A
\end{array} & \text { is the size of the (vertical) } q \text {-axis of the yield ellipse; } \\
A=\frac{p_{c}+p_{t}}{2} & \text { is the size of the (horizontal) } p \text {-axis of the yield ellipse; } \\
\alpha=B / A & \text { is the shape factor of the yield ellipse; } \\
p_{0}=\frac{p_{c}-p_{t}}{2} & \text { is the center of the yield ellipse on the } p \text {-axis; } \\
p_{c} & \text { is the yield stress in hydrostatic compression (always positive); } \\
p_{t} & \text { is the strength of the material in hydrostatic tension. }
\end{array}
$$

The yield surface represents the von Mises circle in the deviatoric stress plane and is an ellipse on the meridional stress plane, as depicted in Figure 2.

The yield surface evolves with a constant $\alpha$ and thus, $\alpha$ can be computed using the initial yield stress in uniaxial compression, $\sigma_{c}^{0}$, the initial yield stress in hydrostatic compression, $p_{c}^{0}$ (the initial value of $p_{c}$ ), and the yield strength in hydrostatic tension, $p_{t}$, by:

$$
\begin{gathered}
\alpha=\frac{3 k}{\left(3 k_{t}+k\right)(3-k)} \\
k=\frac{\sigma_{c}^{0}}{p_{c}^{0}} \\
k_{t}=\frac{p_{t}}{p_{c}^{0}}
\end{gathered}
$$

For a valid yield surface the choice of strength ratios must be such that $k$ has a value between 0 and 3 and $k_{t}$ is positive. In order to define the shape of the yield surface, values are provided to $k$ and 
$k_{t}$ as input for the material model and thus, the necessary $\sigma_{c}^{0}, p_{c}^{0}$ and $p_{t}$ are defined. The values here used are based in the ones determined by [59]. In addition, it uses the plastic part of the stress-strain curve obtained for EPS in a quasi-static uniaxial compression obtained in [61]. $p_{t}$ usually have a weak effect on the numerical results unless the foam is stressed in hydrostatic tension [60]. The strength ratios $k_{t}$ and $k$ were defined as 0.1 and 2.5 , respectively.

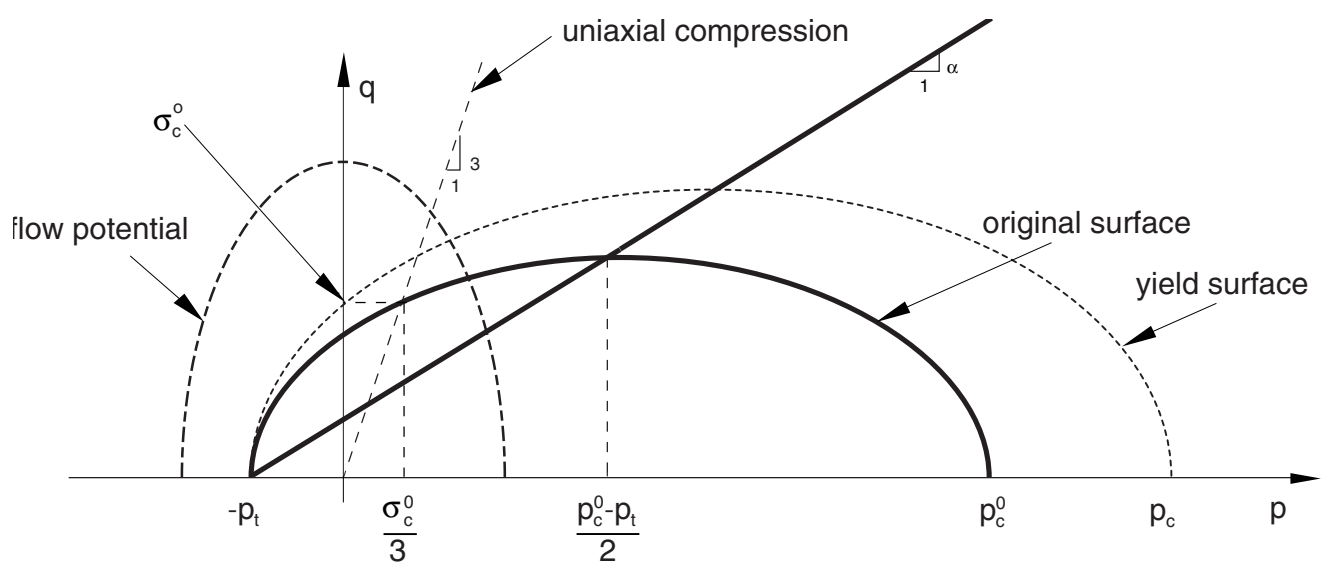

Figure 2. Crushable foam model with volumetric hardening: yield surface and flow potential in the $p-q$ stress plane (adapted from [60]).

On the other hand, ABS is a stiff thermoplastic material very resistant to penetration. ABS was modeled as specified as an isotropic linear-elastic material model, described by Equations (1)-(3). This option is supported by the fact that during an impact the outer shell is mainly responsible for spreading out the impact's concentrated load and generally deforms elastically, which is an acceptable simplification for a shell made from a thermoplastic like ABS. In addition, in the literature, thermoplastic shells are modeled as linear elastic materials, using only non-elastic models to simulate composite shells [62]. The Young's modulus and the Poisson's ratio of ABS are $4 \mathrm{GPa}$ and 0.37, respectively. These are based on the properties used by [37]. The properties have been previously used with success to validate this helmet model [33] and even by other authors [63]. In addition, based on the properties used in this thesis for both ABS and EPS and previously published in $[24,33,63]$ used the same properties to model a helmet, which was validated with success.

\subsubsection{Acceleration Curves}

The comparison between experimental data from energy-absorption tests required by the ECE R22.05 standard and the simulations are in good agreement. This comparison is based on the acceleration recorded at the headform COG, is shown in Figure 3. Overall, there is a good agreement between experiments and simulations for all four impact points. The small differences between experimental and numerical results may be explained by the absence of some neglected components. For instance, the impacted area at point $X$ has several parts that were not modeled such as the visor locking system, the chin strap, the fixation system between the two parts of the shell and the comfort padding that has a considerable thickness at this region. Despite some differences between experimental and numerical impact results, the helmet model was considered adequate enough for the further analyses. 
B

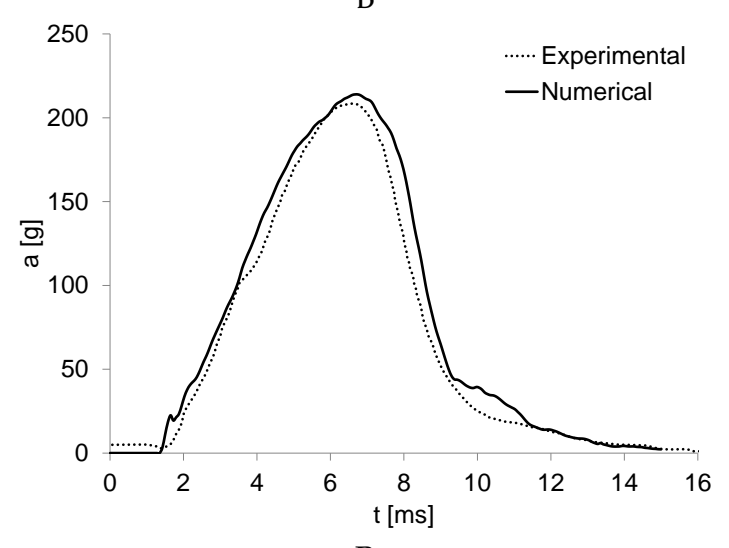

$\mathrm{R}$

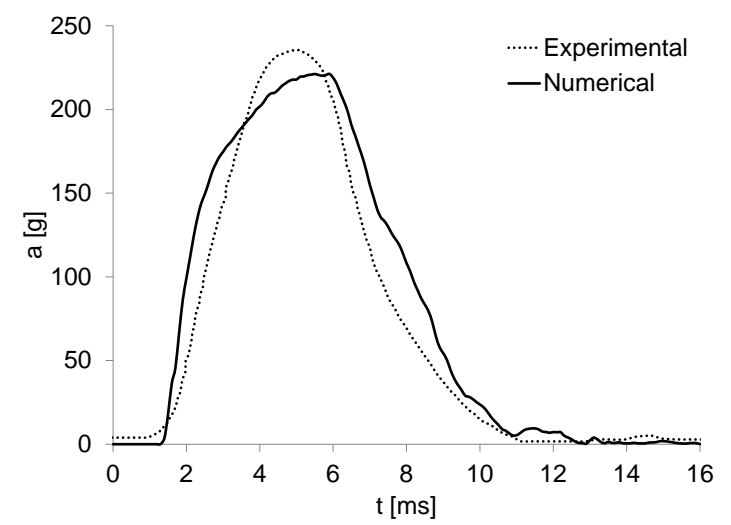

$\mathrm{P}$

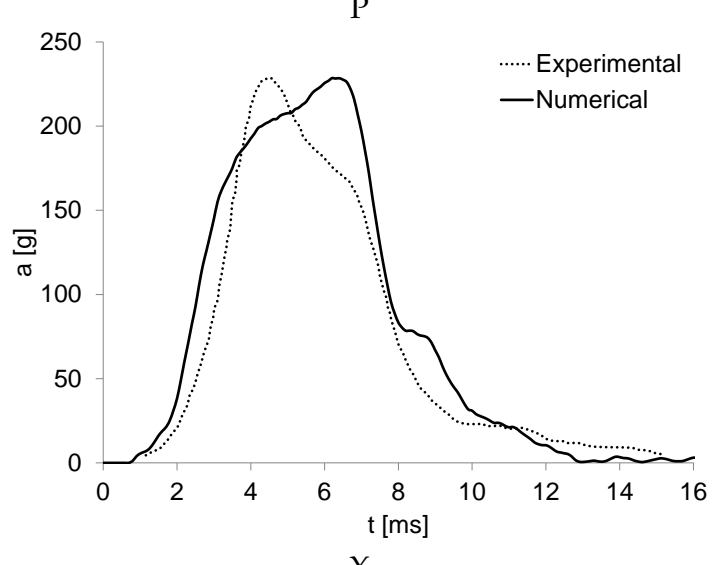

$X$

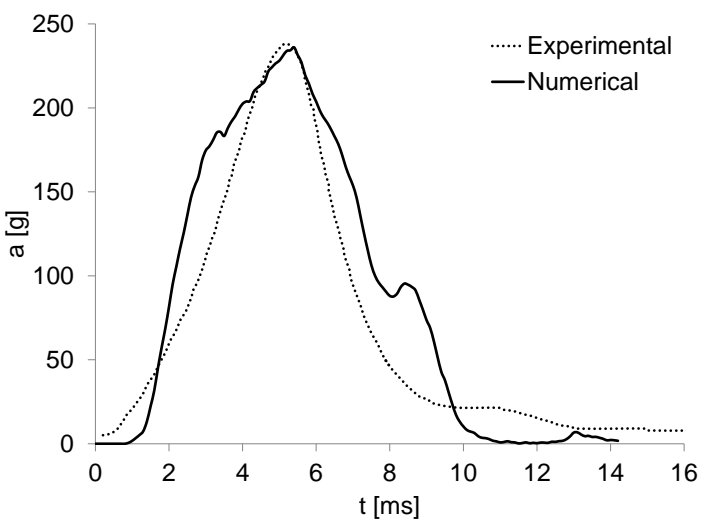

Figure 3. ECE R22.05 impact results-a comparison between experimental and numerical accelerations.

\subsection{Injury Risk Evaluation}

The use of tools, such as FE head models, together with local tissue thresholds seems to be the best way to evaluate the influence of both translational and rotational motion in head structures [64]. The brain response can be analyzed in terms of several parameters, such as pressure and strain. This evaluation consists of determining the risk of head injuries that can possibly occur with a certified helmet. In order to perform such analysis, the experimental data from the impact tests required by ECE R22.05 standard were used to drive YEAHM. This analysis was performed for the four impacts (B, P, R and X) required by the ECE R22.05 standard.

Thus, the acceleration measured in these impacts and presented in Figure 3 was induced to YEAHM's skull. We used the exact same procedure used in validation of YEAHM's brain motion according to the experiments performed by [65]. The head injury criteria and respective thresholds previously reviewed in [4], more specifically the stress and strain based injury criteria are used together with YEAHM to perform an injury risk analysis.

\section{YEAHM}

YEAHM consists of skull, cerebrospinal fluid (CSF) and brain, being constituted by a total of 991,617 quadratic tetrahedral elements. Tetrahedral elements may show volumetric locking, especially in case of soft tissues such as the brain, which are modeled as almost incompressible materials [66]. Thus, artificial stiffening due to incompressibility was always a concern, justifying the refined mesh.

Brain tissue is a very soft, strain rate sensitive, non-linear viscoelastic material, usually assumed to be incompressible due to its high water content. YEAHM's brain tissue mechanical behavior is modeled by a hyper-viscoelastic material model, with a hyperelastic model to describe the non-linear elasticity, combined with a viscoelastic model to describe the time-dependent behavior. The hyperelastic model is defined by a strain energy potential, also known as strain energy density function, which defines 
the strain energy stored in the material per unit of reference volume (initial volume) as function of the strain in the material. Each hyperelastic model has their own strain energy potential, $W$, from which the relationship between stress and strain tensors is derived. The strain energy function, $W$, is usually defined in terms of the invariants $\left(I_{1}, I_{2}, I_{3}\right)$ of the strain tensor, which is itself defined by the deformation gradient tensor, $\mathbf{F}$. This relation is established by the left Cauchy-Green deformation tensor, B:

$$
\mathbf{B}=\mathbf{F F}^{T}
$$

The invariants of $\mathbf{B}$ are defined as:

$$
\begin{gathered}
I_{1}=\operatorname{tr}(\mathbf{B})=\lambda_{1}^{2}+\lambda_{2}^{2}+\lambda_{3}^{2} \\
I_{2}=\frac{1}{2}\left[\operatorname{tr}(\mathbf{B})^{2}-\operatorname{tr}\left(\mathbf{B}^{2}\right)\right]=\lambda_{1}^{2} \lambda_{2}^{2}+\lambda_{2}^{2} \lambda_{3}^{2}+\lambda_{1}^{2} \lambda_{3}^{2} \\
I_{3}=\operatorname{det} \mathbf{B}=J^{2}=(\operatorname{det}(\mathbf{F}))^{2}=\lambda_{1}^{2} \lambda_{2}^{2} \lambda_{3}^{2}
\end{gathered}
$$

where $\lambda_{i}$ are the principal stretches and $J$ is the total volume ratio given by the determinant of the deformation gradient. The Ogden model is used to describe the non-linear mechanical behavior of the brain [67]:

$$
W=\sum_{i=1}^{N} \frac{2 \mu_{i}}{\alpha_{i}^{2}}\left(\bar{\lambda}_{1}^{\alpha_{i}}+\bar{\lambda}_{2}^{\alpha_{i}}+\bar{\lambda}_{3}^{\alpha_{i}}-3\right)+\sum_{i=1}^{N} \frac{1}{D_{i}}(J-1)^{2 i}
$$

where $\bar{\lambda}_{i}$ are the deviatoric principal stretches, which can be obtained through the relation between the total volume ratio $J$ and the principal stretches $\lambda_{i}$,

$$
\bar{\lambda}_{i}=J^{-1 / 3} \lambda_{i}
$$

$N, \mu_{i}, \alpha_{i}$ and $D_{i}$ are material parameters. The initial shear modulus, $\mu_{0}$, can be obtained through Equation (14).

$$
\mu_{0}=\sum_{i=1}^{N} \mu_{i}
$$

The bulk modulus for the Ogden form is given by:

$$
K_{0}=\frac{2}{D_{1}}
$$

Thus, the one-term Ogden hyperelastic function is given by:

$$
W=\frac{2 \mu_{0}}{\alpha_{1}^{2}}\left(\bar{\lambda}_{1}^{\alpha_{1}}+\bar{\lambda}_{2}^{\alpha_{1}}+\bar{\lambda}_{3}^{\alpha_{1}}-3\right)+\frac{1}{D_{1}}(J-1)^{2}
$$

If a material is incompressible, the third strain invariant has a value of 1 , and the strain energy function is only a function of the first two invariants. Thus, an isotropic hyperelastic incompressible material is characterized by a strain-energy density function $W$, which is a function of two principal strain invariants only. The stress-strain relationship is then obtained from a partial derivative of the strain energy potential with respect to deformation gradient tensor $\mathbf{F}$.

The relaxation response is based on a Prony series and the strain energy function is developed in the form of a convolution integral. Thus, in order to model the brain's non-linear elasticity and the time-dependent behavior, the one-term Ogden hyperelastic model and a Prony series are combined: 


$$
W=\frac{2}{\alpha_{1}^{2}} \int_{0}^{t}\left[\mu(t-\tau) \frac{d}{d \tau}\left(\bar{\lambda}_{1}^{\alpha_{1}}+\bar{\lambda}_{2}^{\alpha_{1}}+\bar{\lambda}_{3}^{\alpha_{1}}-3\right)\right] d \tau+\frac{1}{D_{1}}(J-1)^{2}
$$

Hence, the relaxation of the time-dependent shear modulus $\mu(t)$ to describe the viscous response of the tissue is:

$$
\mu(t)=\mu_{0}\left[1-\sum_{k=1}^{n} g_{k}\left(1-e^{-t / \tau_{k}}\right)\right]
$$

where $\mu_{0}$ is the initial shear modulus, $\tau_{k}$ are the characteristic relaxation times and $g_{k}$ are the relaxation coefficients, which can be determined from the experimental data. The parameters used for the one-term Ogden model and for Prony series are based on the ones determined by [68,69]. Table 3 presents the values used to model the brain.

Table 3. Properties used to model the brain.

\begin{tabular}{cccccccc}
\hline$\rho\left[\mathrm{kg} / \mathrm{m}^{3}\right]$ & $\mu[\mathrm{MPa}]$ & $\alpha_{1}$ & $D_{1}\left[\mathrm{MPa}^{-1}\right]$ & $g_{1}$ & $g_{2}$ & $\tau_{1}[\mathrm{~s}]$ & $\tau_{2}[\mathrm{~s}]$ \\
\hline 1040 & 0.012 & 5.0507 & 0.04 & 0.5837 & 0.2387 & 0.02571 & 0.02570 \\
\hline
\end{tabular}

CSF is modeled as a solid with a very low shear modulus and as a hyperelastic material, using the Mooney-Rivlin strain energy potential:

$$
W=C_{10}\left(\bar{I}_{1}-3\right)+C_{01}\left(\bar{I}_{2}-3\right)+\frac{1}{D_{1}}(J-1)^{2}
$$

where $W$ is the strain energy per unit of reference volume; $C_{10}, C_{01}$, and $D_{1}$ are material parameters; and $\bar{I}_{1}$ and $\bar{I}_{2}$ are the first and second deviatoric strain invariants defined as:

$$
\begin{aligned}
& \bar{I}_{1}=J^{-2 / 3} I_{1} \\
& \bar{I}_{2}=J^{-4 / 3} I_{2}
\end{aligned}
$$

The bulk modulus can be obtained through Equation (15). The initial shear modulus is given by:

$$
\mu_{0}=2\left(C_{10}+C_{01}\right)
$$

Table 4 gives the values used to model the CSF. The CSF density used is the same as water since the two are similar. Regarding the values used for the $C_{10}, C_{01}$ and $D_{1}$, these are higher than the ones typically used in the literature. This is normal since YEAHM's CSF global model needs to account for all the internal contents, except the brain. Nevertheless, the relation $C_{10}=0.9 C_{01}$ used by Gilchrist [70] was adopted here.

Table 4. Properties used to model the CSF.

\begin{tabular}{cccc}
\hline$\rho\left[\mathrm{kg} / \mathrm{m}^{\mathbf{3}}\right]$ & $C_{\mathbf{1 0}}[\mathrm{MPa}]$ & $C_{\mathbf{0 1}}[\mathrm{MPa}]$ & $\boldsymbol{D}_{\mathbf{1}}\left[\mathrm{MPa}^{-\mathbf{1}}\right]$ \\
\hline 1000 & 0.9 & 1 & 0.9 \\
\hline
\end{tabular}

For this particular work, there was no need to use a deformable skull. Therefore, it was modeled as rigid body. YEAHM is validated according to the experiments from Nahum et al. [71] and Hardy et al. [65], which are considered benchmark tests and were used to assess YEAHM's intracranial pressure response and brain motion, respectively. Given the complexity and strong non-linearity of the brain tissue's mechanical response, it is unrealistic to expect that one constitutive model will fit all circumstances. Depending on the loading regimes, specific brain tissue properties may be necessary to capture the correct response of brain tissue. Fortunately, the following tests performed in cadavers and 
used for validation were designed to replicate road accidents. A broader and complete description of the model and its validation can be found in Fernandes et al. [39] and Fernandes et al. [52].

\section{Results}

The acceleration measured during the impacts and presented in Figure 3, is used to drive the head model. The output parameters used as injury criteria to assess the helmet are the ones typically indicated in the literature, e.g., hydrostatic pressure and the maximum principal strain [4]. The analysis described below focuses on injury criteria, whose thresholds were exceeded.

\subsection{Impact Point $B$}

Considering the maximum principal strain measured in the brain, a significant risk of injury was identified at the contrecoup region. In the literature, the maximum principal strain thresholds vary between 0.1 and 0.49 [4]. Figure 4 shows a considerable volume where the maximum principal strain value is ranging between 0.1 and 0.4 . The dark region is characterized by maximum principal strain values inferior to 0.1 . Thus, this corresponds to a uninjured region.

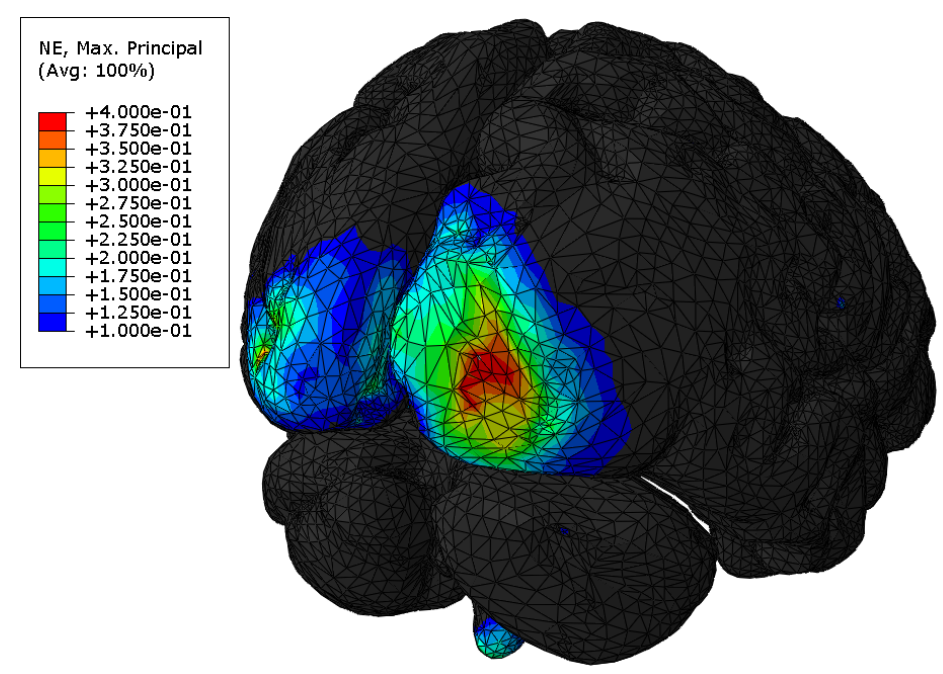

Figure 4. Maximum principal strain at the occipital lobe.

On the other hand, the colored regions are associated with a relevant risk of injury. These represent brain regions where thresholds were exceeded. Regarding the color scale, the red regions are the most probable ones to be injured. It is clear that almost the entire occipital lobe is under high strain values. Thus, it is clear that at least mild brain injuries are an almost certain outcome. In Figure 4 the color transition between blue and green represents an approximate maximum principal strain of 0.2 , which demonstrates a considerable volume of brain tissue experiencing a significant strain. The strain values of 0.18 and 0.21 proposed by $[72,73]$ respectively, represent the most used thresholds for principal strain to predict DAI.

The cumulative strain damage measure (CSDM), which is considered one of the most promising stress-strain based injury criteria, was also evaluated. CSDM is based on the brain's cumulative volume fraction calculation, which has experienced a specific level of stretch (maximum principal strain). Prior to the moment captured in Figure 4, which corresponds to almost $10 \mathrm{~ms}$, a larger brain volume was experiencing a strain higher than 0.15 . A brain volume of approximately $20 \%$ of its total volume experienced a maximum principal strain of 0.15 . This volume is composed mainly by the corpus callosum, some internal regions of the parietal and temporal lobes and the entire occipital lobe. This corresponds to a CSDM level of 20, which is associated to an almost certain mild DAI and close to a moderate-to-severe DAI according to the values presented by [74]. 
The brain pressure was also evaluated. By comparing the brain pressure obtained with YEAHM with the threshold values in the literature [4], a tremendous risk of injury was found. Regarding coup pressure, the limit values range between 90 and $256 \mathrm{kPa}$ depending on the type of injury. In Figure 5 the color limits were defined between 100 and $500 \mathrm{kPa}$. The brain model is almost totally colored, which means that almost the entire brain was subjected to a pressure higher than $100 \mathrm{kPa}$. The dominant color is light green which is equivalent to a pressure higher than $300 \mathrm{kPa}$, which is higher than any threshold in the literature. Therefore, a high risk of severe injuries is identified, reaching dangerous pressure levels.
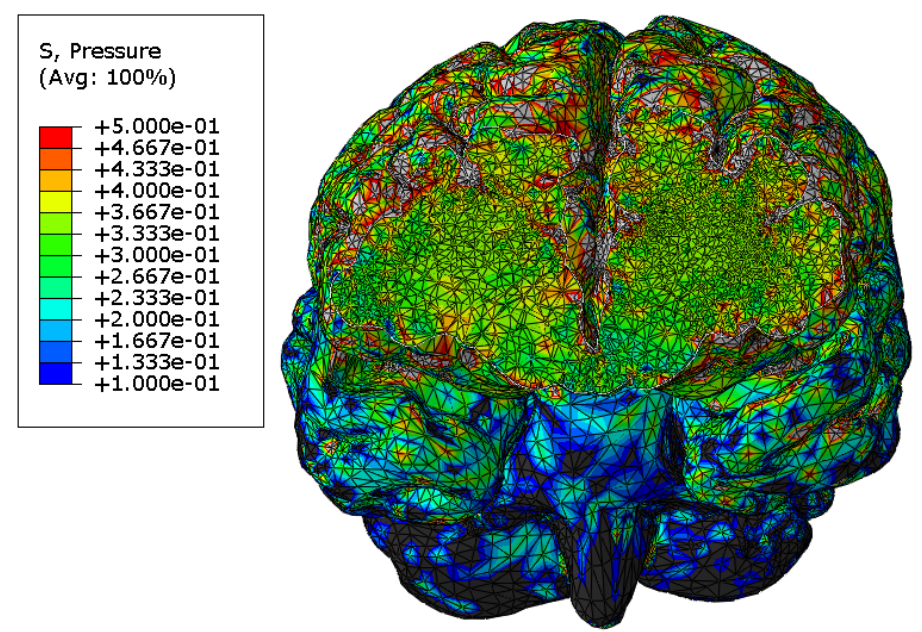

Figure 5. A cut view at the frontal lobe, showing the brain internal pressure in MPa.

The DDM was also evaluated, but the average negative pressure found at the contrecoup region was under $-100 \mathrm{kPa}$ (in absolute value), which is a safe value according to the literature [4]. Nevertheless, a small region with values near $-100 \mathrm{kPa}$ was found at the same area marked red in Figure 4. This region presents the higher value for negative pressure. Thus, it is evident that there exists a relation between these two parameters regarding the contrecoup. However, the volume that sustained a pressure of $-100 \mathrm{kPa}$ was small and did not reach any proposed threshold for DDM. Only the $-76 \mathrm{kPa}$ proposed by [75] for a $50 \%$ risk of MTBI was exceeded.

Additionally, in this exact same region, the maximum von Mises stress was found (Figure 6). The maximum values of von Mises stress, maximum principal strain and negative pressure were found at this region and at the same time of impact, which is approximately $10 \mathrm{~ms}$. Figure 6 shows the occipital lobe experiencing high levels of von Mises stress. The transition between blue and green is characterized by a stress of approximately $40 \mathrm{kPa}$. In addition, the region where the maximum value was found exceeds $100 \mathrm{kPa}$ (light gray volume), reaching a localized maximum of $260 \mathrm{kPa}$, which exceeds any proposed value given in the literature.

In addition, the entire brain experienced an average stress higher than $10 \mathrm{kPa}$, as shown in Figure 7. This demonstrates that the entire brain is at risk and not just the occipital lobe. In the von Mises stress mapping depicted in Figure 7, it is clear that corpus callosum is under a high stress concentration, which clear demonstrates a high injury risk, specifically at this region. 


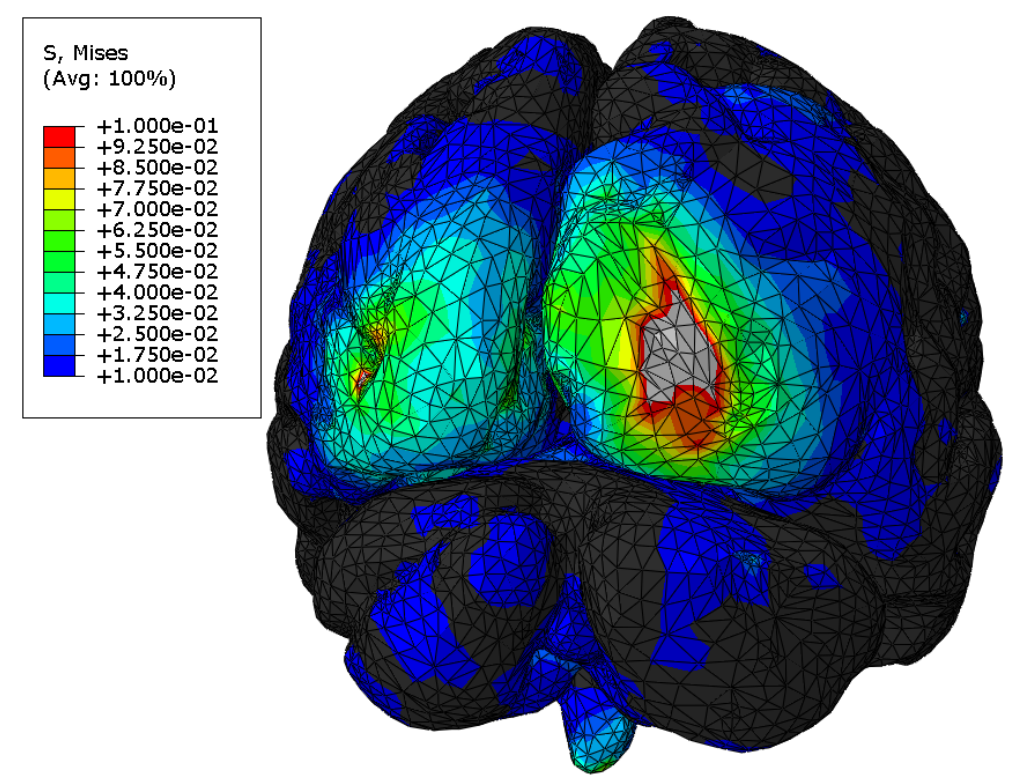

Figure 6. Maximum von Mises stress in MPa at the occipital lobe.

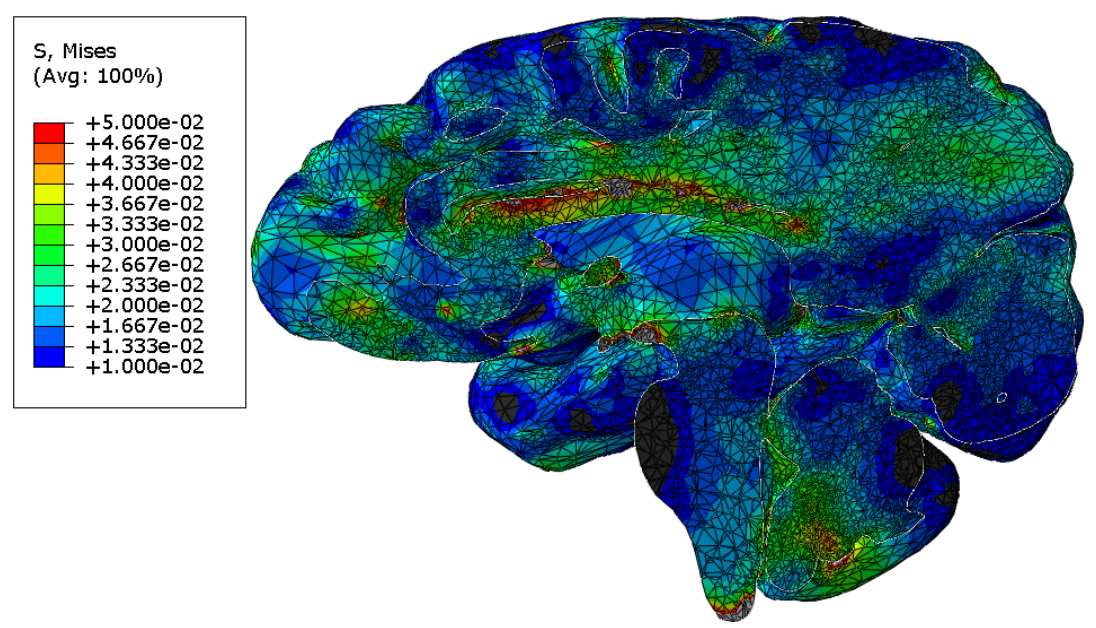

Figure 7. Sagittal cut view at the moment of maximum acceleration—von Mises stress in MPa.

When the peak acceleration in Figure 3 is reached, compression of the frontal lobe and the relative displacement between the occipital lobe and the skull reach their maximums. Then, the rebound immediately starts and the occipital lobe impacts the skull, compressing the brain at the contrecoup region. This is most likely the cause of the maximum von Mises stress. Additionally, during the rebound, the brain tissue stretches at this region, causing the maximum principal strain value.

The CSF strain energy and its pressure were also analyzed and compared with the values proposed in the literature regarding SDH prediction. The maximum strain energy found in the CSF was $6490 \mathrm{~mJ}$, which is higher than the values proposed in the literature [76,77]. For instance, the highest value was proposed by [77], a limit of 4950 mJ. Nevertheless, the value computed with YEAHM may not be feasible to directly compare with injury thresholds, since the global model of CSF incorporates the properties of all the intracranial contents with exception of the brain. Nevertheless, this value may be useful to compare different helmets for the same impact conditions. The authors in [77] also proposed a CSF pressure of $290 \mathrm{kPa}$ as tolerance for SDH. This value was never exceeded, reaching a maximum pressure of $265.8 \mathrm{kPa}$ next to the corpus callosum.

In conclusion, for an impact at point $\mathrm{B}$, a high risk of brain injuries are predicted for this certified helmet. Although there is strong evidence that a standard-approved helmet does not fully protect its 
user in the same impact used to certify it, the remaining three impacts (P, R and $\mathrm{X}$ ) were also analyzed in order to eliminate any dependence on the type of impact.

\subsection{Impact Point $P$}

Similarly to impact point $\mathrm{B}$, the impact at point $\mathrm{P}$ was also evaluated. As in the previous section, the acceleration presented in Figure 3 is used to drive YEAHM. The same output parameters are used to assess the helmet impact performance at this point. Regarding the von Mises stress, two different levels were observed in YEAHM. A lower stress level across the cerebrum reaching an average of $12 \mathrm{kPa}$, and a much higher level in cerebellum. In Figure 8, considering that the transition between blue and green occurs for an approximate value of $25 \mathrm{kPa}$ and that light gray is higher than $60 \mathrm{kPa}$, an injury at the cerebellum is most likely to occur.

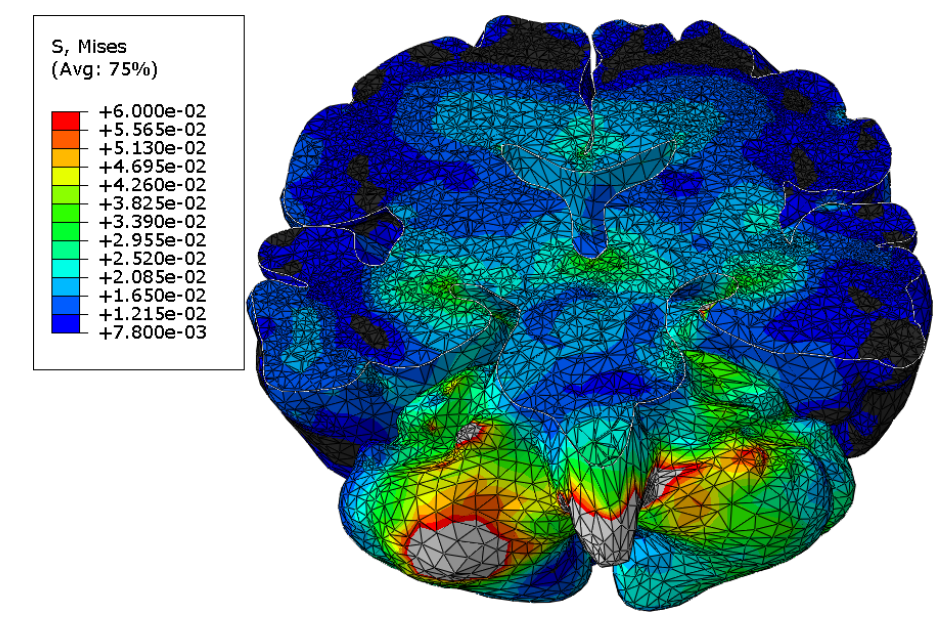

Figure 8. Coronal cut view at the moment of maximum acceleration, showing the von Mises stress in $\mathrm{MPa}$.

Again, the maximum von Mises stress is experienced at the contrecoup region and at the moment of maximum acceleration. The von Mises stress values at the cerebellum and at the base of brainstem were higher than all values available in the literature [4]. Actually, the brainstem seems to be one of the most sensitive regions to von Mises stress, due to the low values proposed as thresholds at this region. For instance, a 50\% probability of concussion was proposed by [75] for von Mises stress values higher than $7.8 \mathrm{kPa}$ in the brainstem. In addition, the value of $8.4 \mathrm{kPa}$ in the corpus callosum, proposed by [41] for a $50 \%$ probability of concussion, was largely exceeded.

As in the case of impact point $B$, the maximum pressure occurred at the coup site, reaching pressure values higher than $295 \mathrm{kPa}$, which is one of the higher TBI thresholds indicated in the literature [4]. The DDM was also evaluated, and the results are very similar to impact $\mathrm{B}$. The average negative pressure found at the contrecoup region was under $-75 \mathrm{kPa}$ (in absolute value), which is a safe value. Nevertheless, the region where the higher negative pressure was found is the same volume (cerebellum and brainstem) where it was found the maximum von Mises stress.

The maximum principal strain was also assessed. Again, its maximum value was found at the same region where the maximum von Mises stress and negative pressure were found (Figure 8). In other words, the maximum values for these were found at the contrecoup region, more specifically at the cerebellum and brainstem. Although the maximum principal strain observed at these regions reaches 0.38 , the brain volume experiencing this strain is small. Additionally, the brain volume experiencing a maximum principal strain higher than 0.15 is less than $5 \%$, which means this is lower than the injury thresholds proposed for CSDM in in the literature [4].

Regarding the relative motion between brain and skull, the maximum was also observed at the cerebellum. However, this was not that significant. The pressure in the CSF was also monitored. This reached a maximum value of $193.3 \mathrm{kPa}$, which is much lower than the value proposed by [77] as a 
tolerance for SDH. In addition, a CSF strain energy value of $4322.6 \mathrm{~mJ}$ was computed. This is lower than the limit proposed by [77]. However, it is higher than the SDH threshold of $4211 \mathrm{~mJ}$ proposed by [76].

This same impact with this same helmet was previously assessed with the other FE head model. The same conditions prescribed for YEAHM were applied to SUFEHM(Strasbourg University Finite Element Head Model) in [24]. Strain energy in the CSF of $4097 \mathrm{~mJ}$ was found with SUFEHM, which is lower than YEAHM. The maximum von Mises stress was located between the brain and the cerebellum and between the cerebellum and the brainstem. This supports the findings obtained with the YEAHM model. Both models predicted the maximum von Mises stress at the same region. Nevertheless, SUFEHM predicted the maximum pressure in occipital area, while YEAHM predicted in the parietal lobe. YEAHM prediction regarding the maximum brain pressure seems more realistic since the impact was on the parietal area.

Additionally, the average von Mises stress found with SUFEHM at the cerebellum was $39.7 \mathrm{kPa}$, which is in accordance with the values predicted with YEAHM at that region. This value corresponds to a $90.2 \%$ risk of moderate DAI, according to SUFEHM's criteria. Again, it is clear that an approved helmet does not protect its user in the same impacts in which it was validated.

\subsection{Impact Point $R$}

The same impact used to certify the previously validated helmet at point $R$ was used to assess it with YEAHM. The experimental acceleration-time history of impact $R$, shown in Figure 3, was used to drive YEAHM. This impact at the back of the head originated high strains in the frontal lobes, opposite to the impact site. Figures 9 and 10 show the maximum principal strain distribution.

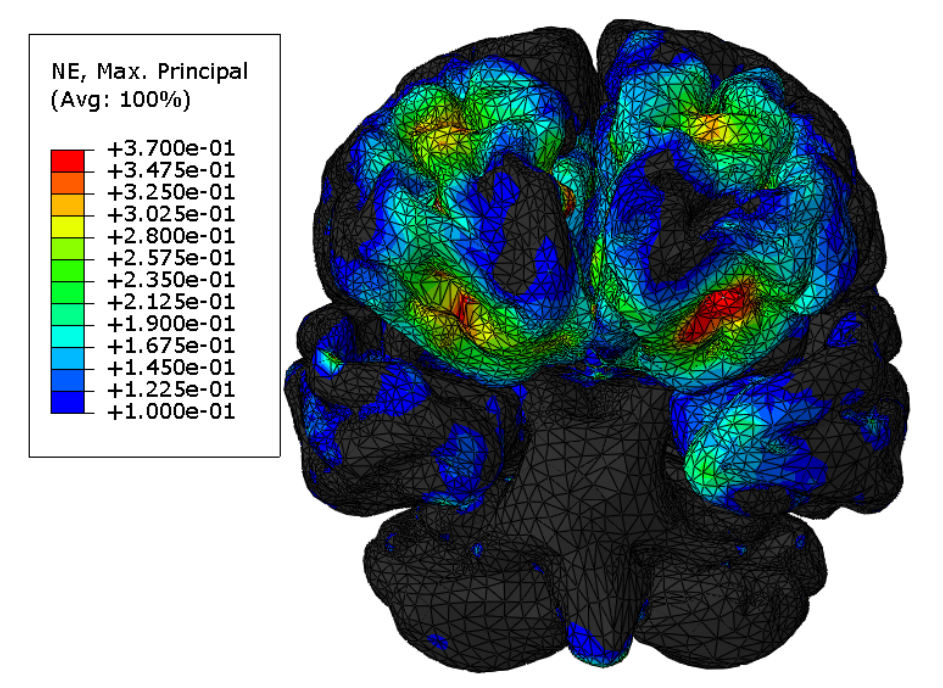

Figure 9. Maximum principal strain reached at the contrecoup site (frontal lobes).

The lower limit was set to 0.1 , since it is the lowest injury threshold given in the literature [4]. Figure 9 shows the start of the rebound, and it is possible to observe a distribution resembling wave propagation. At the end of the rebound, the maximum principal strain was reached, with a relatively localized value of 0.53. This value and even the ones presented in Figures 9 and 10 exceed the injury thresholds presented in [4]. Thus, several forms of TBI, including contusion, concussion and DAI are predicted for this impact. Figure 10 shows the internal distribution of strains higher than 0.1. It is possible to observe the presence of these around the corpus callosum and midbrain. These figures show also the importance of modeling sulci and gyri structures. These make it possible to obtain some patterns in the results that are not possible to observe in a brain model with a smooth spherical surface. 


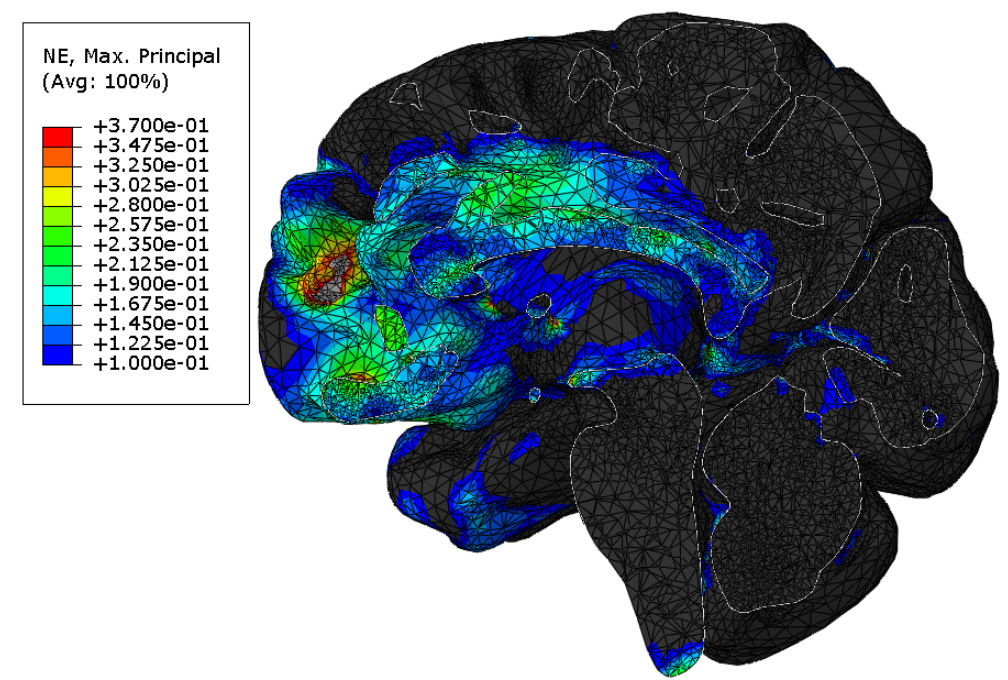

Figure 10. Sagittal cut view showing the internal distribution of the maximum principal strain.

In addition, from the start of the rebound until the end of the acceleration-time history curve, approximately $36 \%$ of the brain experienced a strain of at least $15 \%$. Comparing these values with the ones proposed in the literature, a CSDM level of 36 is enough to cause a moderate-to-severe DAI [74]. Regarding the pressure mapping across the brain, higher values were found, as expected, at the impact zone. At the coup site, pressure values ranging between 329.2 and $363.3 \mathrm{kPa}$ were found, higher than the injury thresholds. Such pressures found in the occipital lobes are likely to originate a severe injury. In addition, a great brain volume experienced pressures higher than $90 \mathrm{kPa}$, such as the occipital lobes, parts of the cerebellum and temporal and parietal lobes. Regarding the DDM, only safe values were observed.

The von Mises stress was also monitored. Its maximum values were observed in the frontal lobes (contrecoup site), with values exceeding all the thresholds presented in [4]. The light gray regions shown in Figure 11 exceed all the values in the literature, determining a high risk of TBI.

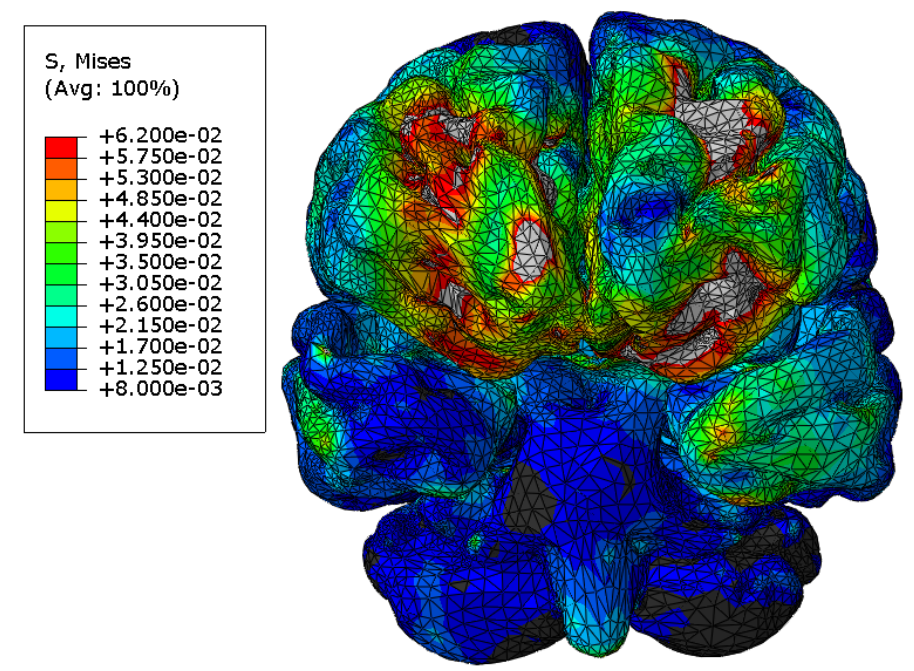

Figure 11. The von Mises stress across the brain in MPa.

Regarding the CSF pressure, the tolerance value of $290 \mathrm{kPa}$ proposed by [77] as the threshold for SDH was reached but not significantly exceeded. This high pressure was found in the CSF at the base of the occipital lobe. This region of the CSF also simulates the junction between falx cerebri and tentorium. The maximum CSF strain energy found was $6911.5 \mathrm{~mJ}$ which is higher than any proposed threshold for SDH. Thus SDH is a probable outcome. 


\subsection{Impact Point X}

Finally, the lateral impact was also assessed. Regarding the von Mises stress, as in other impacts, the maximum value was reached at the contrecoup site, in this case, the temporal lobe opposite to the impact point. Overall, almost the entire brain experienced a value higher than $7.8 \mathrm{kPa}$, which is the lowest injury threshold proposed in the literature [4]. In addition, as shown in Figure 12, the maximum value found in the brain model (light gray) exceeded the highest one proposed in the literature [4]. Thus, brain injuries such as concussion and DAI are likely to occur.

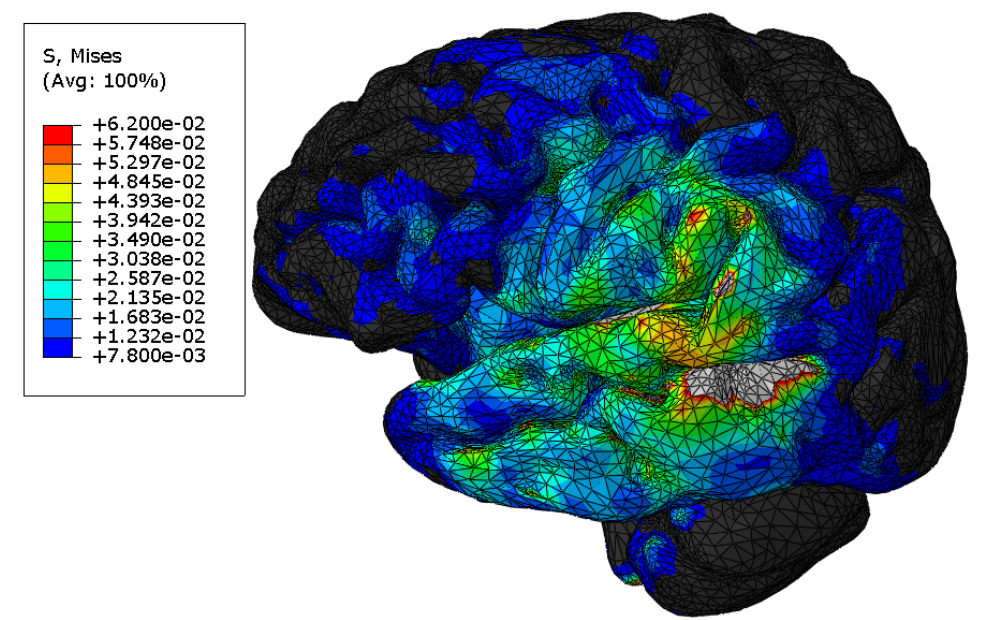

Figure 12. Maximum von Mises stress found at the contrecoup site (in MPa).

As in the other impacts, the pressure reached its maximum at the coup site. Figure 13 shows a coronal cut of the brain, showing the pressure wave propagation across the hemispheres. The low limit of $90 \mathrm{kPa}$ (blue) is the lower injury threshold found in literature (with the exception of negative pressures). In addition, the higher pressure threshold given in this table is $256 \mathrm{kPa}$, which was exceeded for almost an entire hemisphere. Again, several sorts of TBI are an almost certain outcome. Regarding the DDM, none of the limits were exceeded.

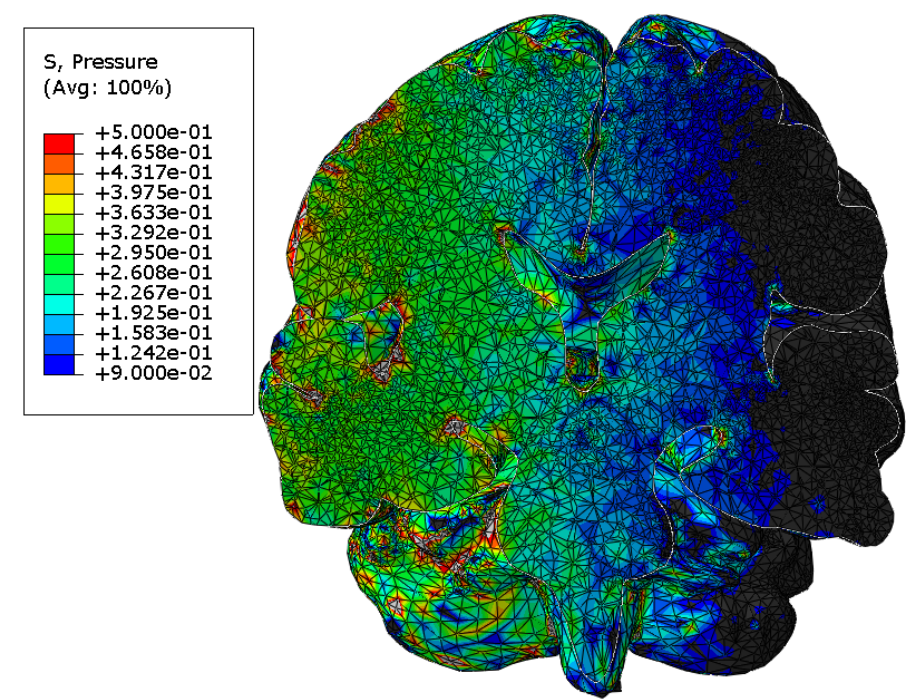

Figure 13. Coronal cut view of the brain showing the pressure wave propagation across the hemispheres (in $\mathrm{MPa}$ ).

In this impact, the maximum principal strain was generally under the values indicated in the literature [4]. However, around the contrecoup region, strains ranging between 0.1 and 0.17 were found. Additionally, exactly in same area of the temporal lobe where it was found the maximum von Mises 
stress, a localized strain of approximately 0.43 was found. Nevertheless, the brain volume experiencing such strain is small and the CSDM limits were not exceeded. Regarding the SDH prediction, both CSF pressure and CSF strain energy were lower than the SDH thresholds proposed in the literature. A pressure of nearly $290 \mathrm{kPa}$ was found at the skull base but did not surpass this value. A value of $3975.5 \mathrm{~mJ}$ was computed for the CSF strain energy, which is close to the threshold but still lower than the limit.

\section{Discussion and Conclusions}

In this work, the efficacy of a motorcycle helmet certified by ECE R22.05 standard is assessed, using numerical models. Both finite element models of a motorcycle helmet and of a human head were employed to carry out such analysis. The analysis consisted of simulating the same impacts required by the standard and subject the FE head model to the accelerations measured during impact. In other words, the finite element model of the human head is used as an injury prediction tool.

These models can even be used to optimize safety gear according to a specific criterion. For instance, the works carried out by Tinard et al. [23] and Fernandes et al. [34]. The author in Tinard et al. [23] also performed a similar analysis by simulating the impact tests required by the ECE R22.05 standard. Results showed that even if a helmet passes the impact tests required by the ECE R22.05 standard, there is a high risk of injury associated with these same impacts. This study allowed to establish the potential of FEH head models in helmet design and the problems associated with the standards criteria.

A similar study was also performed with the same FE head model used by Tinard et al. [23] for a different motorcycle helmet, and the results were similar [24]. Both predicted a significant risk of brain injury. Nevertheless, in Fernandes et al. [24], the analysis was only carried out for impact point P. In this work, a similar analysis is carried out for the same helmet but with a different FE head model, YEAHM. This work is a broader analysis, assessing the four impacts required by ECE R22.05, the impact points $B, P, R$ and $X$.

Several types of head injuries were predicted in these four impacts, such as contusions, concussions and DAI. Some limitations of the standard are underscored from what was seen with YEAHM. This supports the premise that the current criteria for helmet standards are not optimal.

In conclusion, the analysis of these four impacts showed that by reproducing the same impacts that are assessed by the ECE R22.05 standard, it is evident that a certified helmet cannot protect its user from suffering brain injuries. This clearly shows that simple injury criteria such as PLA and HIC are not enough to assess the protection provided by helmets. Therefore, it can be concluded that a motorcyclist wearing an approved helmet can suffer brain injuries in the same impact that was used to certify the helmet. The conclusions here withdrawn are supported by other studies, where similar analyses led to the same conclusions [23,24].

The use of detailed tools, such as FE head models, together with local tissue thresholds seems to be one of the best ways to evaluate the influence of both linear and rotational motion in head structures [64]. It is possible that future methods used to assess head injury risk and protective head gear will rely on the predictions from numerical head models. This is an excellent way to study injury mechanisms, focusing on brain reaction to different kinematics and loading inputs, analyzing the brain response in terms of parameters such as intracranial pressure and brain strain. This is the best way to implement smart helmet design.

Author Contributions: Conceptualization, F.A.O.F. and R.J.A.d.S.; methodology, F.A.O.F. and R.J.A.d.S.; software, F.A.O.F., R.J.A.d.S., M.P. and J.W.; validation, F.A.O.F.; formal analysis, F.A.O.F.; investigation, F.A.O.F.; data curation, F.A.O.F.; writing — original draft preparation, F.A.O.F.; writing—review and editing, F.A.O.F., R.J.A.d.S., M.P. and J.W.; visualization, F.A.O.F., R.J.A.d.S., M.P. and J.W. All authors have read and agreed to the published version of the manuscript.

Funding: This work was supported by the projects UIDB/00481/2020 and UIDP/00481/2020 (FCT) Fundação para a Ciência e a Tecnologia; and CENTRO-01-0145-FEDER-022083-Centro Portugal Regional Operational 
Programme (Centro2020), under the PORTUGAL 2020 Partnership Agreement, through the European Regional Development Fund.

Acknowledgments: Research under grant CEECIND/01192/2017 acknowledges the support given by Fundação para a Ciência e a Tecnologia (FCT).

Conflicts of Interest: The authors declare no conflict of interest.

\section{References}

1. World Health Organization. Global Status Report on Road Safety. 2018. Available online: https://www.who. int/violence_injury_prevention/road_safety_status/2018/en/ (accessed on 13 February 2020).

2. EPSR. Road Fatality Statistics in the EU (Infographic). Available online: https://www.europarl.europa.eu/ news/en/headlines/society/20190410STO36615/road-fatality-statistics-in-the-eu-infographic (accessed on 13 February 2020).

3. United Nations. ECE Regulation 22.05-Uniform Provision Concerning the Approval of Protective Helmets and Their Visors for Driver and Passengers of Motor Cycles and Mopeds. Available online: www.unece.org/ fileadmin/DAM/trans/main/wp29/wp29regs/r022r4e.pdf (accessed on 13 February 2020).

4. Fernandes, F.A.O.; Alves de Sousa, R.J. Head injury predictors in sports trauma-A state-of-the-art review. J. Eng. Med. 2015, 229, 592-608. [CrossRef] [PubMed]

5. Bellora, A.; Krauss, R.; van Poolen, L. Meeting Interior Head Impact Requirements: A Basic Scientific Approach. SAE Trans. 2001, 110, 383-408.

6. Kleiven, S. Influence of Impact Direction to the Human Head in Prediction of Subdural Hematoma. J. Neurotrauma 2003, 20, 365-379. [CrossRef] [PubMed]

7. Kleiven, S. Influence of direction and duration of impacts to the human head evaluated using the finite element method. In Proceedings of the IRCOBI Conference, Prague, Czech Republic, 21-23 September 2005; pp. 41-57.

8. Feist, F.; Gugler, J.; Arregui-Dalmases, C.; del Pozo de Dios, E.; Lopez-Valdes, F.; Deck, D.; Willinger, R. Pedestrian collisions with flat-fronted vehicles: Injury patterns and importance of rotational accelerators as a predictor for traumatic brain injury (TBI). In Proceedings of the 21st International Conference on the Enhanced Safety of Vehicles, Stuttgart, Germany, 15-18 June 2009; pp. 1-19.

9. Fenner, H., Jr.; Thomas, D.J.; Gennarelli, T.; Pintar, F.A.; Becker, E.B.; Newman, J.A.; Yoganandan, N. Final Report of Workshop on Criteria for Head Injury and Helmet Standards; Department of Neurosurgery, Medical College of Wisconsin: Milwaukee, WI, USA, 2005.

10. Kim, G.H.; Lee, O.S.; Yoo, S.S. Experimental study on impact absorbing performance of motorcycle helmets. KSME Int. J. 1997, 11, 292-299. [CrossRef]

11. Kleiven, S.; von Holst, H. Consequences of head size following trauma to the human head. J. Biomech. 2002, 35, 153-160. [CrossRef]

12. Newman, J.A. Head injury criteria in automotive crash testing. SAE Tech. Pap. 1980. [CrossRef]

13. Newman, J. On the Use of the Head Injury Criterion (HIC) in Protective Headgear Evaluation. SAE Tech. Pap. 1975. [CrossRef]

14. Johnson, G.I. Investigations on impact testing of head injury protection helmets. Int. J. Crashworthiness 2000, 5, 491-502. [CrossRef]

15. Zhao, W.; Ji, S. Brain strain uncertainty due to shape variation in and simplification of head angular velocity profiles. Biomech. Model. Mechanobiol. 2017, 16, 449-461. [CrossRef]

16. Aare, M.; Kleiven, S.; Halldin, P. Injury tolerances for oblique impact helmet testing. Int. J. Crashworthiness 2004, 9, 15-23. [CrossRef]

17. King, A.; Yang, K.; Zhang, L.; Hardy, W.; Viano, D. Is head injury caused by linear or angular acceleration? In Proceedings of the IRCOBI Conference, Lisbon, Portugal, 25-26 September 2003; pp. 1-10.

18. Gennarelli, T.A. Head injury in man and experimental animals: Clinical aspects. Acta Neurochir. Suppl. 1983, 32, 1-13. [PubMed]

19. Margulies, S.S.; Thibault, L.E. A proposed tolerance criterion for diffuse axonal injury in man. J. Biomech. 1992, 25, 917-923. [CrossRef]

20. Newman, J. The biomechanics of head trauma and the development of the modern helmet. How far have we really come? In Proceedings of the IRCOBI Conference, Prague, Czech Republic, 21-23 September 2005. 
21. Pratellesi, A.; Turrin, S.; Haag, T.; Scippa, A.; Baldanzini N. On the effect of testing uncertainties in the homologation tests of motorcycle helmets according to ECE 22.05. Int. J. Crashworthiness 2011, 16, 523-536. [CrossRef]

22. Shuaeib, F.M.; Hamouda, A.M.S.; Radin Umar, R.S.; Hamdan, M.M.; Hasmi, M.S.J. Motorcycle helmet part I. Biomechanics and computational issues. J. Mater. Process. Technol. 2002, 123, 406-421. [CrossRef]

23. Tinard, V.; Deck, C.; Willinger, R. New methodology for improvement of helmet performance during impacts with regards to biomechanical criteria. Mater. Des. 2012, 37, 79-88. [CrossRef]

24. Fernandes, F.A.O.; Alves de Sousa, R.J.; Willinger, W.; Deck, C. Finite Element Analysis of Helmeted Impacts and Head Injury Evaluation with a Commercial Road Helmet. In Proceedings of the IRCOBI Conference, Gothenburg, Sweden, 11-13 September 2013; pp. 431-442.

25. Schmitt, K.U.; Niederer, P.F.; Cronin, D.S.; Morrison, B., III; Muser, M.H.; Walz, F. Head Injuries. In Trauma Biomechanics; Springer: Cham, Switzerland, 2019.

26. Aare, M.; Kleiven, S.; Halldin, P. Injury criteria for oblique helmet impacts. In Proceedings of the IRCOBI Conference, Lisbon, Portugal, 25-26 September 2003; pp. 349-350.

27. Deck, C.; Baumgartner, B.; Willinger, R. Helmet Optimisation on head-helmet modelling. Struct. Mater. 2003, 13, 319-328.

28. Forero Rueda, M.A.; Cui, L.; Gilchrist, M.D. Optimisation of energy absorbing liner for equestrian helmets. Part I: Layered foam liner. Mater. Des. 2009, 30, 3405-3413. [CrossRef]

29. Kleiven, S. A parametric study of energy absorbing foams for head injury prevention. In Proceedings of the 20th International Technical Conference on the Enhanced Safety of Vehicles Conference, Lyon, France, 18-21 June 2007.

30. Prasartthong, N.; Koetniyom, S.; Carmai, J. Development of Motorcycle Helmet for Pre-school Children Using Metal Foam. In Proceedings of the 9th Thai Society of Mechanical Engineers, International Conference on Mechanical Engineering, Phuket, Thailand, 11-14 December 2018.

31. Han, Y.; He, W.; Shi, L.; Wu, H.; Pan, D.; Huang, H. Helmet protective performance via reconstruction of electric two-wheeler rider's head-to-ground impact accidents. Int. J. Crashworthiness 2019. [CrossRef]

32. Hynčík, L.; Bońkowski, T.; Lv, W. Development of a simple motorcyclist helmet finite element model. Int. J. Veh. Saf. 2018, 10, 277-287. [CrossRef]

33. Fernandes, F.A.O.; Alves de Sousa, R.J. Finite element analysis of helmeted oblique impacts and head injury evaluation with a commercial road helmet. Struct. Eng. Mech. 2013, 48, 661-679. [CrossRef]

34. Fernandes, F.A.O.; Alves de Sousa, R.J.; Ptak, M.; Migueis, G. Helmet Design Based on the Optimization of Biocomposite Energy-Absorbing Liners under Multi-Impact Loading. Appl. Sci. 2019, 9, 735. [CrossRef]

35. Cui, L.; Forero Rueda, M.A.; Gilchrist, M.D. Optimisation of energy absorbing liner for equestrian helmets. Part II: Functionally graded foam liner. Mater. Des. 2009, 30, 3414-3419. [CrossRef]

36. Mills, N.J.; Gilchrist, A. Motorcycle helmet shell optimisation. In Proceedings of the Association for Advancement of Automotive Medicine Conference, Portland, OR, USA, 5-7 October 1992; pp. 149-162.

37. Pinnoji, P.K.; Mahajan, P. Impact analysis of helmets for improved ventilation with deformable head model. In Proceedings of the IRCOBI Conference, Madrid, Spain, 14-16 September 2006; pp. 159-170.

38. Pinnoji, P.K.; Haider, Z.; Mahajan, P. Design of motorcycle helmets: Computational fluid and impact dynamics studies. Int. J. Crashworthiness 2008, 13, 265-278. [CrossRef]

39. Fernandes, F.A.O.; Tchepel, D.; Alves de Sousa, R.J.; Ptak, M. Development and validation of a new finite element human head model: Yet Another Head Model (YEAHM). Eng. Comput. 2018, 35, 447-496. [CrossRef]

40. Horgan, T.J.; Gilchrist, M.D. The creation of three-dimensional finite element models for simulating head impact biomechanics. Int. J. Crashworthiness 2003, 8, 353-366. [CrossRef]

41. Kleiven, S. Predictors for traumatic brain injuries evaluated through accident reconstructions. In Proceedings of the 51st Stapp Car Crash Conference, San Diego, CA, USA, 29-31 October 2007; pp. 81-114.

42. Mao, H.; Zhang, L.; Jiang, B.; Genthikatti, V.V.; Jin, X.; Zhu, F.; Makwana, R.; Gill, A.; Jandir, G.; Singh, A.; et al. Development of a Finite Element Human Head Model Partially Validated with Thirty Five Experimental Cases. J. Biomech. Eng. 2013, 135, 111002. [CrossRef]

43. Sahoo, D.; Deck, C.; Willinger, R. Brain injury tolerance limit based on computation of axonal strain. Accid. Anal. Prev. 2016, 92, 53-70. [CrossRef] 
44. Takhounts, E.G.; Ridella, S.A.; Hasija, V.; Tannous, R.E.; Campbell, J.Q.; Malone, D.; Danelson, K.; Stitzel, J.; Rowson, S.; Duma, S. Investigation of Traumatic Brain Injuries Using the Next Generation of Simulated Injury Monitor (SIMon) Finite Element Head Model. Stapp Car Crash J. 2008, 52, 1-31.

45. Zhang, L.; Yang, K.H.; King, A.I. Comparison of brain responses between frontal and lateral impacts by finite element modelling. J. Neurotrauma 2001, 18, 21-30. [CrossRef]

46. Khanuja, T.; Unni, H.N. Intracranial pressure-based validation and analysis of traumatic brain injury using a new three-dimensional finite element human head model. Proc. Inst. Mech. Eng. H 2020, 234, 3-15. [CrossRef]

47. Saboori, P.; Walker, G. Brain Injury and Impact Characteristics. Ann. Biomed. Eng. 2019, 47, $1982-1992$. [CrossRef] [PubMed]

48. Giudice, J.S.; Zeng, W.; Wu, T.; Alshareef, A.; Shedd, D.F.; Panzer, M.B. An Analytical Review of the Numerical Methods Used for Finite Element Modeling of Traumatic Brain Injury. Ann. Biomed. Eng. 2019, 47, 1855-1872. [CrossRef] [PubMed]

49. Yu, C.; Wang, F.; Wang, B.; Li, L.; Li, F. A Computational Biomechanics Human Body Model Coupling Finite Element and Multibody Segments for Assessment of Head/Brain Injuries in Car-To-Pedestrian Collisions. Int. J. Environ. Res. Public Health 2020, 17, 492. [CrossRef] [PubMed]

50. Migueis, G.; Fernandes, F.A.O.; Ptak, M.; Ratajczak, M.; Alves de Sousa, R.J. Detection of bridging veins rupture and subdural haematoma onset using a finite element head model. Clin. Biomech. 2019, 63, 104-111. [CrossRef]

51. Toma, M.; Nguyen, P.D.H. Coup-contrecoup brain injury: Fluid-structure interaction simulations. Int. J. Crashworthiness 2019. [CrossRef]

52. Fernandes, F.A.O.; Alves de Sousa, R.J.; Ptak, M. Head Injury Simulation in Road Traffic Accidents; Springer International Publishing: Cham, Switzerland, 2018.

53. Brands, D.W.A.; Thunnissen, J.G.M.; Wismans, J.S.H.M. Modelling head injury countermeasures: A 3D helmet model. In Proceedings of the AGARD Meeting on Impact Head Injury, Mescalero, NM, USA, 7-9 November 1996.

54. Pinnoji, P.K.; Mahajan, P. Analysis of impact-induced damage and delamination in the composite shell of a helmet. Mater. Des. 2010, 31, 3716-3723. [CrossRef]

55. Cernicchi, A.; Galvanetto, U.; Iannucci, L. Virtual modelling of safety helmets: Practical problems. Int. J. Crashworthiness 2008, 13, 451-467. [CrossRef]

56. Tinard, V.; Deck, C.; Willinger, R. Modelling and validation of motorcyclist helmet with composite shell. Int. J. Crashworthiness 2012, 17, 209-215. [CrossRef]

57. Shuaeib, F.M.; Hamouda, A.M.S.; Hamdan, M.M.; Radin Umar, R.S.; Hashmi, M.S.J. Motorcycle helmet: Part II, Materials and design issues. J. Mater. Process. Technol. 2002, 123, 422-431. [CrossRef]

58. Vallée, H.; Hartemann, F.; Thomas, C.; Tarriére, C.; Patel, A.; Got, C. The fracturing of helmet shells. In Proceedings of the IRCOBI Conference, Delft, The Netherlands, 4-6 September 1984; pp. 99-109.

59. Mills, N.J.; Wilkes, S.; Derler, S.; Flisch, A. FEA of oblique impact tests on a motorcycle helmet. Int. J. Impact Eng. 2009, 36, 913-925. [CrossRef]

60. ABAQUS 6.10 Documentation; Hibbitt, Karlsson \& Sorensen, Inc.: New York, NY, USA, 2010.

61. Fernandes, F.A.O.; Jardin, R.T.; Pereira, A.B.; Alves de Sousa, R.J. Comparing the mechanical performance of synthetic and natural cellular materials. Mater. Des. 2015, 82, 335-341. [CrossRef]

62. Fernandes, F.A.O.; Alves de Sousa, R.J. Motorcycle helmets-A state-of-the-art review. Accid. Anal. Prev. 2013, 56, 1-21. [CrossRef] [PubMed]

63. Mustafa, H.; Pang, T.Y.; Perret-Ellena, T.; Subic, A. Finite element bicycle helmet models development. Procedia Technol. 2015, 20, 91-97. [CrossRef]

64. Mordaka, J.; Kleiven, S.; van Schijndel de Nooij, M.; de Lange, R.; Casanova, L.J.G.; Carter, E.L.; von Holst, H. The importance of rotational kinematics in pedestrian head to windshield impacts. In Proceedings of the IRCOBI Conference, Maastricht, The Netherlands, 19-21 September 2007; pp. 83-94.

65. Hardy, W.N.; Foster, C.D.; Mason, M.J.; King, K.H.; King, A.I.; Tashman, S. Investigation of head injury mechanisms using neutral density technology and high-speed biplanar X-ray. Stapp Car Crash J. 2001, 45, 337-368. [PubMed]

66. Miller, K.; Chinzei, K. Mechanical properties of brain tissue in tension. J. Biomech. 2002, 35, 483-490. [CrossRef] 
67. Ogden, R.W. Large deformation isotropic elasticity-on the correlation of theory and experiment for incompressible rubber like solids. Proc. R. Soc. Lond. A Math. Phys. Sci. 1972, 326, 565-584.

68. Rashid, B.; Destrade, M.; Gilchrist, M.D. Mechanical characterization of brain tissue in compression at dynamic strain rates. J. Mech. Behav. Biomed. Mater. 2012, 10, 23-38. [CrossRef]

69. Rashid, B.; Destrade, M.; Gilchrist, M.D. Hyperelastic and viscoelastic properties of brain tissue in tension. In Proceedings of the ASME 2012 International Mechanical Engineering Congress \& Exposition, Houston, TX, USA, 9-15 November 2012; pp. 9-15.

70. Gilchrist, M.D. Modelling and Accident Reconstruction of Head Impact Injuries. Key Eng. Mater. 2003, 245, 417-432. [CrossRef]

71. Nahum, A.M.; Smith, R.; Ward, C.C. Intracranial pressure dynamics during head impact. In Proceedings of the 21st Stapp Car Crash Conference, New Orleans, LA, USA, 19-21 October 1977; pp. 339-366.

72. Wright, R.M.; Ramesh, K.T. An axonal strain injury criterion for traumatic brain injury. Biomech. Model. Mechanobiol. 2012, 11, 245-260. [CrossRef]

73. Bain, B.C.; Meaney, D.F. Tissue-level thresholds for axonal damage in an experimental model of central nervous system white matter injury. J. Biomech. Eng. 2000, 122, 615-622. [CrossRef]

74. Bandak, F.A.; Zhang, A.X.; Tannous, R.E.; DiMasi, F.; Masiello, P.; Eppinger, R. SIMon: A simulated injury monitor: Application to head injury assessment. In Proceedings of the 17th International Technical Conference on the Enhanced Safety of Vehicles, Amsterdam, The Netherlands, 4-7 June 2001.

75. Zhang, L.; Yang, K.; King, A. A proposed injury threshold for mild traumatic brain injury. J. Biomech. Eng. 2004, 126, 226-236. [CrossRef] [PubMed]

76. Marjoux, D.; Baumgartner, D.; Deck, C.; Willinger, R. Head injury prediction capability of the HIC, HIP, SIMon and ULP criteria. Accid. Anal. Prev. 2008, 40, 1135-1148. [CrossRef] [PubMed]

77. Deck, C.; Willinger, R. Head injury prediction tool for predictive systems optimization. In Proceedings of the 7th European LS-DYNA Conference, Salzburg, Austria, 14-15 May 2009.

(C) 2020 by the authors. Licensee MDPI, Basel, Switzerland. This article is an open access article distributed under the terms and conditions of the Creative Commons Attribution (CC BY) license (http:/ / creativecommons.org/licenses/by/4.0/). 